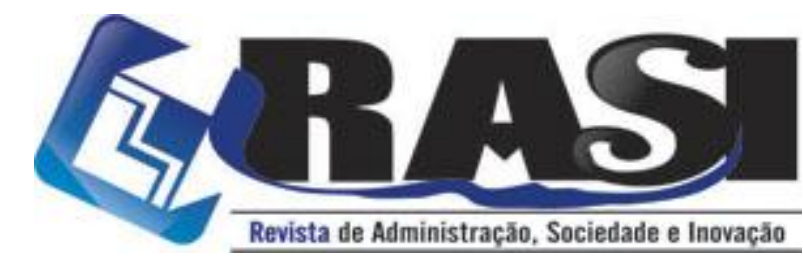

http://www.rasi.uff.br

RASI, Volta Redonda/RJ, v. 1, n. 1, pp. 53-69, Jul./Dez. 2015.

\title{
Investimentos em Ações de Responsabilidade Social no Brasil: uma Análise Quantitativa
}

Eduardo Aguiar Silva - Universidade Federal de São João del-Rei eduardoufsj@hotmail.com

Denise Carneiro dos Reis Bernardo - Universidade Federal de São João del-Rei

Fabrício Molica Mendonça - Universidade Federal de São João del-Rei

João Paulo de Brito Nascimento - Universidade Federal de Alfenas

Resumo: Esta pesquisa teve por objetivo investigar se os investimentos em ações de responsabilidade social variam de acordo com setor econômico das empresas que os realizam. Para tanto, foram abordadas algumas iniciativas surgidas no Brasil com o propósito de apoiar e disseminar o movimento pela responsabilidade social: o balanço social do IBASE, a ABNT NBR 16001, o ISE BOVESPA, a NBC T 15, bem como a Lei $\mathrm{n}^{\mathrm{o}} 11.638$ de 2007. A partir do referencial teórico e no intuito de esclarecer a questão proposta foram analisados de forma quantitativa os investimentos realizados ao longo de 10 anos em educação, saúde, cultura, alimentação, combate à fome e segurança alimentar e aqueles em ações de responsabilidade social rotuladas como "outros", ou seja, ações que não foram discriminadas pelas empresas. A amostra contemplou os investimentos de 42 empresas que publicam regularmente seus balanços sociais, segregando-se em: 10 organizações do setor bancário, 29 do setor energético, 02 do setor siderúrgico e 01 do setor petrolífero. Os resultados mostraram que as empresas do setor siderúrgico tenderam a realizar investimentos na faixa dos $\mathrm{R} \$ 10$ milhões, preferencialmente em atividades educacionais e de saúde e saneamento. Já os setores bancário e petrolífero privilegiaram as ações culturais e educacionais com recursos acima de R\$ 100 milhões. E as empresas do setor energético foram as únicas que realizaram investimentos em todas as faixas. De modo geral, esses resultados sugerem que há uma relação entre o perfil de investimentos em ações de responsabilidade social e o setor econômico.

Palavras-Chave: Responsabilidade Social, Setores Econômicos, Brasil.

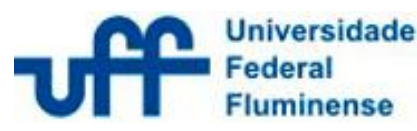

R. Desembargador Ellis Hermydio Figueira, 783, Bloco A, sl. 218, Aterrado.

27213-415 - Volta Redonda, RJ - Brasil

www.uff.br

Copyright @ 2015 RASI. Todos os direitos, até mesmo de tradução, são reservados. É permitido citar parte de artigos sem autorização prévia, desde que seja identificada a fonte. 


\section{Investimentos em Ações de Responsabilidade Social no Brasil: uma Análise Quantitativa}

\section{INTRODUÇÃO}

As discussões sobre o papel social das empresas remontam, de acordo com a literatura, ao início do século XX (Borger, 2001; Oliveira, 2008; Tenório, 2006). Esses questionamentos intensificaram-se a partir de 1960, quando a sociedade civil norteamericana iniciou um movimento de boicote à aquisição de produtos e ações das empresas que apoiavam a guerra do Vietnã (Tinoco, 1984). Na Europa, a sociedade civil se manifestou exigindo das empresas uma postura mais ética na realização dos negócios como, por exemplo, no movimento estudantil de 1968 na França (1985; Tinoco, 2001).

Nesse contexto, a realização de ações sociais pelas empresas voltadas para a comunidade e, consequentemente, a divulgação dessas ações por meio de relatórios ganhou destaque e tornou-se lei em diversos países europeus. Surgem, então, os primeiros estudos voltados para a formulação do conceito de responsabilidade social.

Segundo Ferrell, Fraedrich e Ferrel (2001) e Srour (2000), a responsabilidade social empresarial consiste na participação da empresa em ações diretamente relacionadas à comunidade. Isso sem descuidar dos interesses dos stakeholders internos. Esse termo ganhou visibilidade na mídia brasileira no final da década de 1990. Em 1997, o sociólogo Hebert de Souza, o "Betinho", representando o Instituto Brasileiro de Análises Sociais e Econômicas (IBASE), em parceria com outras organizações, lançou uma campanha para a divulgação anual do relatório de responsabilidade social, o balanço social (Sucupira, 2009). De fato, além de tornar "pública a responsabilidade social empresarial” (IBASE, 2009), a “(...) publicação de um balanço social oferece uma proposta de diálogo com os diferentes públicos envolvidos no negócio da empresa que o adota" (Instituto Ethos, 2009b).

Desde então, têm surgido no Brasil diversas iniciativas com o intuito de estimular as empresas na adoção dos preceitos da responsabilidade social e, consequentemente, de divulgar essas ações por meio do balanço social "instrumento legitimado perante a sociedade" brasileira (Bernardo, 2010, p. 24).

A partir da análise desse contexto, da revisão de literatura sobre responsabilidade social empresarial e dos dados disponíveis nos balanços sociais surgiu a seguinte questão: os investimentos em ações de responsabilidade social variam de acordo com o setor econômico das empresas que os realizam? No intuito de elucidar esse questionamento, foram analisados de forma quantitativa os investimentos em responsabilidade social realizados pelas empresas de capital aberto dos setores bancário, energético, petrolífero e siderúrgico localizadas no Brasil. A escolha desses setores se justifica pelo fato de reunirem empresas que divulgam regularmente seus investimentos em ações de responsabilidade social por meio da publicação de seus balanços sociais desde 1996.

\section{AÇÕES PARA INCENTIVAR A REALIZAÇÃO E DIVULGAÇÃO DAS PRÁTICAS DE RESPONSABILIDADE SOCIAL: UM ENFOQUE NO MEIO EMPRESARIAL BRASILEIRO}


Nos últimos anos surgiram no Brasil diversas iniciativas com o intuito de incentivar as empresas na adoção dos preceitos da responsabilidade social. Uma dessas iniciativas foi a criação, em 2004, pela Associação Brasileira de Normas Técnicas (ABNT), da Norma Brasileira de Responsabilidade Social, a ABNT NBR 16001. Essa norma tem por objetivo estabelecer critérios para um sistema da gestão da responsabilidade social (Associação Brasileira de Normas Técnicas - ABNT, 2004). A norma aborda, dentre outras questões, aspectos relativos à ética, à atenção aos anseios dos stakeholders, à promoção pela organização da cidadania, à busca pelo desenvolvimento sustentável e à transparência das atividades. A Norma Brasileira de Responsabilidade Social aplica-se a todos os tipos e portes de organização e permite àquelas que fizerem uso dela que busquem a certificação de seu sistema de gestão da responsabilidade social (ABNT, 2004).

Há na Norma Brasileira de Responsabilidade Social questões que merecem uma análise mais criteriosa. A primeira diz respeito à diferença entre ação social e o que a norma denomina "aspectos de responsabilidade social". De acordo com Oliveira (2008, p. 69), "a ação social pode até ser parte das ações de responsabilidade social de uma empresa, mas a RSC ${ }^{i}$ não se limita a ela". Enquanto as ações sociais são os investimentos em projetos não ligados diretamente aos negócios da empresa, visando apenas o bem-estar da comunidade, as ações de responsabilidade social configuram-se como investimentos em ações portadoras de valores considerados mais consistentes e fomentadores de capital social direcionadas aos diversos stakeholders da organização (Ashley, 2005; Garcia, 2004; Goldstein, 2007).

Ainda em relação a esse assunto, outra diferenciação necessária para a formação do conceito de responsabilidade social é a sua distinção de filantropia. De acordo com Goldstein (2007, p. 57) na filantropia "o apoio ao próximo costuma basear-se em boas intenções e donativos materiais, sem exigência de contrapartidas e pouca intenção de divulgação". Já na "gestão da responsabilidade social, a empresa, ao contrário, tende a acompanhar seus investimentos no projeto [...] e buscar a sustentabilidade, sempre com a preocupação de dar visibilidade a suas ações". De acordo com a ABNT NBR 16001 (2004, p. 2) ação social é: "atividade voluntária realizada pela organização em áreas tais como assistência social, alimentação, saúde, educação, esporte, cultura, meio ambiente e desenvolvimento comunitário". E ações são definidos como (ABNT, 2004, p. 2): "elemento das relações, processos, produtos e serviços de uma organização, que podem interagir com o meio ambiente, contexto econômico e contexto social."

Resgatadas, então, as definições da Norma Brasileira de Responsabilidade Social, a ABNT NBR 16001, e traçando-se um comparativo, entre as definições de ações de responsabilidade social e ações filantrópicas expostas por Ashley (2005), Garcia (2004), Goldstein (2007) e Oliveira (2008) detectam-se algumas contradições.

A primeira contradição diz respeito à definição de ação social. A norma deixa claro que "ação social" é uma atividade voluntária. Mas não explicita o mesmo em relação ao "aspecto da responsabilidade social". Tanto a ação social quanto as ações de responsabilidade social ou aspectos da responsabilidade social são ações de caráter voluntário realizadas pelas empresas. Porém, essas ações diferenciam-se quanto à abrangência.

Conforme Goldstein (2007, p. 57) se essas ações constituem-se como "doações a pessoas ou a instituições, mas sem exigência de contrapartidas e pouca intenção de divulgação", caracterizam-se como ações de caráter filantrópico. Como afirma Oliveira 
(2008, p. 144) "Caridade não é responsabilidade social".

No tocante à definição de "aspecto da responsabilidade social: Elemento das relações, processos, produtos e serviços de uma organização, que podem interagir com o meio ambiente, contexto econômico e contexto social" (ABNT, 2004, p. 2), pode-se fazer o mesmo questionamento: a empresa tem a intenção de "acompanhar seus investimentos no projeto, direcionar os objetivos de maneira estratégica, identificar os pontos críticos e buscar a sustentabilidade, sempre com a preocupação de dar visibilidade a suas ações" (Goldstein, 2007, p. 57). Caso a resposta seja afirmativa então, serão ações ou aspectos de responsabilidade social. Caso contrário, conclui-se que não.

Verifica-se, pelas argumentações expostas, que o texto da Norma Brasileira de Responsabilidade Social é ambíguo, quanto à definição de "ação social" e no tocante aos "aspectos de responsabilidade social". Visto que é uma norma de âmbito nacional seria importante uma revisão dos conceitos adotados. Caso contrário há risco tanto da auditoria externa para a certificação, quanto da própria norma não terem propósito, pois, o que pode ser tudo, pode ao mesmo tempo, ser nada.

Outro ponto que merece atenção na norma diz respeito ao desempenho da responsabilidade social. O tópico 2.3 define desempenho da responsabilidade social como: "síntese dos desempenhos ambientais, econômicos e sociais da organização, de forma integrada, levando-se em consideração todas as partes interessadas" (ABNT, 2004, p. 2).

O desempenho econômico de uma empresa pode ser medido pelo retorno sobre o patrimônio líquido e retorno sobre o ativo, por exemplo. Mas como seriam medidos os desempenhos ambientais e sociais? Quais parâmetros devem ser adotados?

Outra questão, de acordo com a (ABNT, 2004, p. 7): "os requisitos desta Norma são genéricos para que possam ser aplicados a todas as organizações" (ABNT, 2004, p. 7). No entanto, alguns requisitos são tão genéricos que podem ocasionar falhas na avaliação do processo, podendo afetar, em última instância, a credibilidade da certificação.

Outro incentivo as práticas de responsabilidade social foi o Índice de Sustentabilidade Empresarial (ISE), desenvolvido pela Bolsa de Valores do Estado de São Paulo (BOVESPA), que visa demonstrar o retorno de uma carteira de ações de empresas localizadas no Brasil engajadas em ações de responsabilidade social e sustentabilidade empresarial. Esse índice tem como foco os investidores que procuram empresas socialmente responsáveis, sustentáveis e rentáveis para a aplicação de seus recursos (BOVESPA, 2009).

Segundo a BOVESPA (2009, p. 35): “o ISE é um "selo de qualidade"”. Nesse sentido, a Comissão das Comunidades Europeias (2001) afirma que o reconhecimento de uma empresa socialmente responsável, por meio da sua inscrição em um índice bolsista de valores éticos, pode refletir positivamente na cotação de suas ações.

Como mencionado anteriormente, essa é mais uma iniciativa surgida nos últimos anos com o intuito de incentivar e auxiliar as empresas no alcance de melhores desempenhos, em termos de sustentabilidade financeira aliada às ações de responsabilidade social e ambiental. Entretanto, ressalta-se que a composição do Índice de Sustentabilidade Empresarial (ISE) possui dois pontos obscuros. Um deles refere-se aos "critérios de exclusão". Segundo as regras do ISE uma empresa será excluída do índice (BOVESPA, 2009, p. 5): "Se, durante a vigência da carteira, a empresa emissora entrar em regime de recuperação judicial ou falência (...)" e "Se, durante a vigência da 
carteira, ocorrer algum acontecimento que altere significativamente seus níveis de sustentabilidade e responsabilidade social, o Conselho do ISE poderá decidir pela sua exclusão da carteira do índice".

Contudo, não há nenhuma ponderação em relação à participação de empresas dos setores de tabaco, armas e bebidas alcoólicas. Esse fato resultou na saída do Instituto Brasileiro de Análises Sociais e Econômicas (IBASE) do conselho, em abril de 2005. Também, não consta nos "critérios de exclusão" do ISE nenhuma ponderação relativa à participação dos setores de "papel e celulose, energia elétrica e siderurgia, cujas atividades causam impactos ambientais significativos e, portanto, possuem práticas questionáveis em termos de sustentabilidade" (Com Ciência, 2006). Outro ponto obscuro se diz à transparência do processo. Os questionários respondidos pelas empresas não são divulgados. Isso seria crucial para que a sociedade possa monitorar se as respostas dadas pelas organizações correspondem à realidade de suas práticas (Com Ciência, 2006).

Cabe mencionar que o Índice de Sustentabilidade Empresarial ainda gera polêmicas. Conforme nota divulgada no sítio da BOVESPA (2009): “O Instituto Ethos de Empresas e Responsabilidade Social está suspenso do Conselho Deliberativo do ISE no período da carteira 2008/2009." Com a suspensão do Instituto Ethos e com a saída, em 2005, do IBASE - organizações da sociedade civil que são referências em termos de responsabilidade social no Brasil - fica estabelecido um cenário nebuloso e repleto de incertezas (Instituto Ethos, 2009b).

A consolidação de uma sociedade democrática está baseada, dentre outros fatores, no diálogo. Considerando que a ação em questão é uma iniciativa que visa auxiliar as empresas no alcance de melhores desempenhos em termos de responsabilidade social, sustentabilidade financeira e ambiental, o diálogo torna-se um ponto nevrálgico. Apenas por meio dele é possível conciliar os interesses e exigências de todos os atores envolvidos no processo.

Ainda no campo das conquistas em prol da transparência das informações de caráter social sobre empresas no Brasil, há de se considerar a ação do Conselho Federal de Contabilidade (CFC) que, em 2004, lançou a norma técnica "NBC T 15 Informações de Natureza Social e Ambiental". Essa norma apresenta conceitos e procedimentos aplicados de Contabilidade, com objetivo de auxiliar as organizações na divulgação das suas ações de responsabilidade social (Conselho Federal de Contabilidade - CFC, 2009).

De acordo com a NBC T 15, entendem-se como informações de natureza social e ambiental, aquelas relacionadas à geração e a distribuição de riqueza; aos recursos humanos; à interação da entidade com o ambiente externo e à interação com o meio ambiente.

Um ponto que merece destaque na NBC T 15 é a preocupação com a transparência das informações. Nesse sentido, o tópico 15.3 .3 expõe que a demonstração de Natureza Social e Ambiental "deve ser objeto de revisão por auditor independente, e ser publicada com o relatório deste, quando a entidade for submetida a esse procedimento". Considera-se que essa regra gera credibilidade e legitimidade ao demonstrativo, visto que as informações contidas nele serão passíveis de auditoria. Ademais, essa iniciativa pode representar uma alternativa para evitar a crítica "balanço social é mera peça de marketing empresarial".

Finalmente, um instrumento simples e consolidado no meio empresarial brasileiro que visa auxiliar as empresas a atenderem aos preceitos da ABNT NBR 
16001 - ou seja, registrar, documentar, divulgar e dar transparência ao processo - é o balanço social.

Froes e Melo Neto (1999) lembram que a responsabilidade social pode ser vista como um compromisso da empresa com a sociedade. E nessa relação a empresa deve prestar contas pelo uso dos recursos da sociedade que utiliza: recursos naturais, financeiros, capacidade de trabalho dos seus funcionários e serviços prestados pelo Estado.

O balanço social pode auxiliar as empresas a prestar contas dos projetos, benefícios e ações sociais desenvolvidos pelas organizações. Ele é conhecido também como relatório de sustentabilidade ou relatório de responsabilidade social. Segundo Tinoco (2001, p. 14): "Balanço Social é um instrumento de gestão e de informação que visa evidenciar, da forma mais transparente possível, informações econômicas e sociais, do desempenho das entidades, aos mais diferenciados usuários, entre estes os funcionários."

O balanço social é uma ferramenta de gestão que reúne dados qualitativos e quantitativos sobre as relações entidade/ambiente (Kroetz, 2000). Os indicadores contidos nesse balanço podem auxiliar na elaboração do planejamento estratégico da organização nos Estados Unidos, Bélgica, França, Portugal e Canadá, (Cappellin \& Giuliani, 1999).

Destaca-se que as informações contidas nesse relatório devem ser diretas, simples e transparentes, permitindo aos diversos stakeholders conhecer e avaliar as ações realizadas pela empresa (Tinoco, 2001). Além de tornar "pública a responsabilidade social empresarial” (IBASE, 2009) a “(...) publicação de um balanço social oferece uma proposta de diálogo com os diferentes públicos envolvidos no negócio da empresa que o adota" (Instituto Ethos, 2009b). Esse demonstrativo comunica os efeitos sociais e ambientais das ações econômicas para determinados grupos (Gray, Kouhy \& Lavers, 1987, p. 10 apud Murthy, 2008).

No Brasil, duas instituições são referências no movimento pela realização e divulgação de práticas de responsabilidade social: o Instituto Ethos de Responsabilidade Social e, ate 2010, o Instituto Brasileiro de Análises Sociais e Econômicas, o IBASE.

O Instituto Ethos tem como propósito apoiar e consolidar o movimento pela responsabilidade social no país. Para tanto, criou, com a participação de colaboradores, os "Indicadores Ethos de Responsabilidade Social". Esses indicadores são apresentados em forma de um questionário dividido em sete grandes temas: valores, transparência e governança; público interno; meio ambiente; fornecedores; consumidores e clientes; comunidade, governo e sociedade (Instituto Ethos, 2009b). Segundo o Instituto Ethos (2009b), esses indicadores constituem-se numa ferramenta de gestão e planejamento executada por meio de autodiagnóstico. A sua principal finalidade é auxiliar as empresas a gerenciarem os impactos sociais e ambientais decorrentes de suas atividades.

Já o IBASE, para estimular a disseminação e consolidação das práticas de responsabilidade social, procurava mostrar aos empresários e à sociedade a importância da elaboração e divulgação do balanço social, documento a ser apresentado anualmente em um único modelo. Essa medida visava garantir um padrão mínimo de informações e assegurar uma avaliação e divulgação adequadas, bem como a possibilidade de comparações. Segundo Bernardo (2010, p. 24), o modelo de balanço social do IBASE era o "instrumento mais utilizado pelas empresas para a divulgação das ações de responsabilidade social" no Brasil. A elaboração e publicação do balanço social do 
IBASE, ate 2010, e dos Indicadores Ethos de Responsabilidade Social são ferramentas importantes e complementares no processo de divulgação e disseminação da responsabilidade social.

Merecem destaque, também, as mudanças advindas com a Lei $\mathrm{n}^{\circ} 11.638$, de 28 de dezembro de 2007 (Brasil, 2007). Essa legislação altera, revoga e introduz novos dispositivos à Lei das Sociedades por Ações e permite que novas normas e procedimentos contábeis sejam expedidos pela Comissão de Valores Mobiliários $(\mathrm{CVM})$. Uma das alterações dessa legislação foi a inclusão da demonstração do valor adicionado (DVA) como publicação obrigatória para todas as companhias de capital aberto.

De acordo com o art. 188, inciso II da Lei $\mathrm{n}^{\circ} 11.638 / 2007$, a DVA compreende (Brasil, 2007): "o valor da riqueza gerada pela companhia, a sua distribuição entre os elementos que contribuíram para a geração dessa riqueza, tais como empregados, financiadores, acionistas, governo e outros, bem como a parcela da riqueza não distribuída".

Essa iniciativa corresponde a um avanço na divulgação de informações contábeis no Brasil. Isso porque a DVA constituí-se numa ferramenta importante, na medida em que apresenta um conjunto de elementos que permitem a análise e avaliação, de forma abrangente, da geração da riqueza criada pela empresa e consequentemente, da sua distribuição.

Como mencionado anteriormente, essas são algumas iniciativas surgidas nos últimos anos que buscam incentivar e auxiliar as empresas no alcance de melhores desempenhos, em termos de sustentabilidade financeira aliada às ações de responsabilidade social e ambiental. Dentre essas iniciativas, destacava-se o modelo de balanço social do IBASE que, de acordo com Torres (1998 apud Freire \& Silva, 2001), contém essencialmente dados quantitativos e permite a comparação entre diferentes empresas e uma avaliação de uma mesma corporação, ao longo dos anos. Ademais, esse demonstrativo pode auxiliar no cumprimento dos preceitos da ABNT NBR 16001, do ISE BOVESPA, da NBC T 15 bem como da Lei no 11.638 de 27 de dezembro de 2007. Isso porque o balanço social atende à exigência da divulgação presente em todas as iniciativas abordadas neste trabalho. Além disso, representa um passo inicial na busca de transparência dos investimentos em responsabilidade social realizados pelas empresas no país. Assim, no intuito de responder à questão proposta, optou-se por utilizar neste trabalho os dados disponíveis nos relatórios anuais das empresas dos setores estudados.

\section{METODOLOGIA}

O objetivo principal desse trabalho foi verificar se os investimentos em ações de responsabilidade social variam de acordo com o setor econômico das empresas que os realizam. Trata-se de um ponto importante na medida em que essa informação pode dar subsídios a políticas públicas e às próprias empresas para avaliar seus investimentos e tomar decisões no estabelecimento de suas estratégias sociais.

Entre as técnicas existentes para determinação de perfil utilizou-se, nesse trabalho, a análise de correspondência. Segundo Carvalho e Struchiner (1992), essa técnica caracteriza-se como uma análise exploratória de dados que permite a visualização gráfica das relações mais importantes dentro de um grande conjunto de variáveis. Essa representação gráfica é denominada "mapa perceptual" e sua 
interpretação define os perfis das variáveis estudadas (Greenacre \& Hastie, 1984; Lourenço, 1997).

Embora seja considerada uma técnica descritiva e exploratória, a análise de correspondência simplifica dados complexos, impossíveis de serem revelados pela análise estatística simples.

No intuito de facilitar a obtenção das informações para efetuar as análises, a amostra foi formada considerando-se dois aspectos: $\left(1^{\circ}\right)$ seriam analisados apenas os investimentos feitos em ações de responsabilidade social por empresas de capital aberto, no período estudado. A observância desses dois critérios permitiu formar uma amostra não probabilística composta por 42 empresas, sendo 10 do setor bancário, 29 do setor energético, 02 do setor siderúrgico e 01 do setor petrolífero.

Foram analisados os investimentos em ações de responsabilidade social destinados à cultura; educação; esporte; saúde e saneamento; alimentação, combate a fome e segurança alimentar e a outras ações de responsabilidade social que não foram discriminadas. Esses investimentos foram escolhidos devido à regularidade com que foram realizados. A análise foi dividida em dois blocos, de acordo com os montantes investidos por empresa: o dos investimentos de até $\mathrm{R} \$ 20$ milhões anuais, que são os realizados em esporte; saúde e saneamento e alimentação, combate a fome e segurança alimentar e o dos investimentos de valor superior a 20 milhões, que são os feitos em educação; cultura e em ações de responsabilidade social rotuladas como "outros" nos balanço social.

Os dados foram coletados dos balanços sociais das empresas estudadas. O período de análise compreendeu os anos de 1998 a 2014. Foram tabuladas e analisadas as informações de 277 balanços sociais. Os relatórios de administração das empresas que compõem a amostra foram consultados com o objetivo de auxiliar na interpretação dos resultados.

\section{RESULTADOS E DISCUSSÕES}

Os resultados foram expostos da seguinte forma: em um primeiro momento, foram analisados os investimentos em ações direcionadas ao esporte, saúde e saneamento e alimentação, combate a fome e segurança alimentar. Em um segundo momento, foram analisados os investimentos em ações de responsabilidade social destinados à educação, cultura e em ações de responsabilidade social rotuladas como "outros". Ambas as análises foram realizadas por faixas de investimentos (até R\$ 10 milhões, $\mathrm{R} \$ 20$ milhões, $\mathrm{R} \$ 50$ milhões e acima de $\mathrm{R} \$ 100$ milhões).

A primeira análise envolveu as empresas que fizeram investimentos até R\$ 10 milhões em ações de esporte, saúde e saneamento e alimentação, combate a fome e segurança alimentar, considerando-se os setores que compõem a amostra, como representa a Tabela 1 .

Tabela 1:

Frequência do número de empresas classificadas de acordo com os setores econômicos que realizaram investimentos até $\mathbf{R}$ \$ 10 milhões nas ações de esporte, saúde e saneamento e alimentação, combate a fome e segurança alimentar

\begin{tabular}{llll}
\hline \multirow{3}{*}{ Setores } & Ações & & \\
\cline { 2 - 4 } & Esporte & Saúde e Saneamento & $\begin{array}{l}\text { Alimentação, } \\
\text { combate a fome e }\end{array}$ \\
\hline
\end{tabular}




\begin{tabular}{llll}
\hline & & & \\
\hline Bancário & 7 & 6 & 8 \\
Energético & 28 & 27 & 28 \\
Siderúrgico & 2 & 2 & 2 \\
\hline
\end{tabular}

Fonte: Elaborada a partir dos dados da pesquisa (2014).

Pelo fato dos setores econômicos serem representados por uma variável categórica com três níveis, espera-se que, no máximo, dois componentes expliquem a variabilidade total. A Tabela 2 apresenta resultados referentes à análise dos componentes principais da tabela 1 .

Tabela 2:

\section{Análise dos componentes principais da tabela de contingência}

\begin{tabular}{llll}
\hline Componente & Autovalor & Proporção & Proporção acumulada \\
\hline 1 & 0.0017 & 0.9972 & 0.9972 \\
2 & 0.0000 & 0.0028 & 1.0000 \\
\hline Total & 0.0017 & & \\
\hline
\end{tabular}

Fonte: Elaborada a partir dos dados da pesquisa (2014).

De acordo com os resultados da Tabela 2, verifica-se que a porcentagem da variabilidade total é explicada pelo $1^{\circ}$ componente $(99,72 \%)$. Esse resultado evidencia uma alta dependência dos níveis das variáveis da categoria "setores" com os níveis das variáveis "ações". Graficamente, essa revelação pode ser explicada em um único eixo. Contudo, por questões usuais de interpretação preferiu-se construir os mapas bidimensionais (Figura 1).

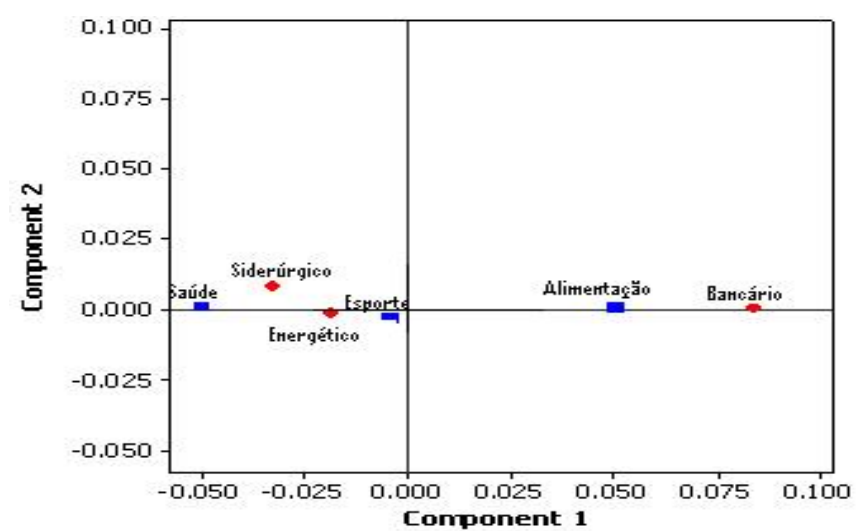

Figura 1. Mapa perceptual do perfil dos investimentos em ações de responsabilidade social até $R$ \$ 10 milhões de acordo com o setor econômico

Fonte: Elaborada a partir dos dados da pesquisa (2014).

Por meio da análise do mapa perceptual (Figura 1) pode-se verificar a discriminação dos investimentos em ações de responsabilidade social de acordo com os setores econômicos. Esse fato pode ser observado pela formação dos grupos, separados em quadrantes diferentes.

Os resultados provenientes do mapa perceptual também demonstraram que houve uma tendência das empresas do setor siderúrgico de realizarem investimentos na 
faixa de R\$ 10 milhões em ações de responsabilidade social focadas em saúde. Já o setor energético patrocinou eventos na área esportiva. A esse respeito, vale observar que os relatórios de administração das empresas desse setor estudadas no período mostram que foram patrocinadas atividades esportivas para crianças e adolescentes.

Além disso, o mapa perceptual exposto na Figura 1 evidencia a tendência de investimentos pelas empresas do setor bancário em ações de alimentação, combate à fome e segurança alimentar. De fato, como mostram os resultados do mapa perceptual, talvez por influência das políticas de incentivos como o Programa Fome Zero, a partir de 2003 e especificamente em 2005, observou-se um grande investimento em projetos dessa natureza. Destaca-se que só o Banco do Brasil, em 2005, atendeu por meio desse programa 2.635 municípios brasileiros (Relatório Anual do Banco do Brasil, 2005). Também foram analisados os investimentos na faixa de $\mathrm{R} \$ 20$ milhões destinados às atividades esportivas, de saúde e saneamento e alimentação, combate a fome e segurança alimentar (Tabela 3 e Tabela 4).

Tabela 3:

Frequência do número de empresas classificadas de acordo com os setores econômicos que realizaram investimentos até $R$ \$ 20 milhões nas ações de esporte, saúde e saneamento e alimentação, combate a fome e segurança alimentar

\begin{tabular}{llll}
\hline \multirow{2}{*}{ Setores } & Ações & Saúde e Saneamento & $\begin{array}{l}\text { Alimentação, combate } \\
\text { a fome e segurança } \\
\text { alimentar }\end{array}$ \\
\hline Bancário & 3 & 4 & 1 \\
Energético & 0 & 2 & 0 \\
Petrolífero & 1 & 1 & 1 \\
\hline
\end{tabular}

Fonte: Elaborada a partir dos dados da pesquisa (2014).

Seguindo a mesma linha de análise adotada na discussão dos resultados da Tabela 2, os resultados da Tabela 4, também, justificam a construção do mapa bidimensional (Figura 2).

Tabela 4:

Análise dos componentes principais da tabela de contingência

\begin{tabular}{llll}
\hline Componente & Autovalor & Proporção & Proporção acumulada \\
\hline 1 & 0.1797 & 0.8443 & 0.8443 \\
2 & 0.0331 & 0.1557 & 1.0000 \\
\hline Total & 0.2128 & & \\
\hline
\end{tabular}

Fonte: Elaborada a partir dos dados da pesquisa (2014). 


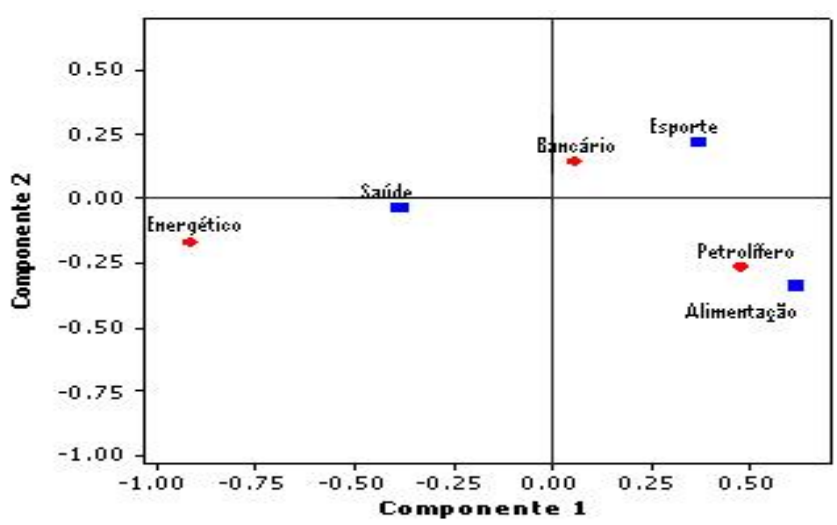

Figura 2. Mapa perceptual do perfil dos investimentos em ações de responsabilidade social até R\$ 20 milhões de acordo com o setor econômico

Fonte: Elaborada a partir dos dados da pesquisa (2014).

De acordo com os resultados apresentados no mapa perceptual da Figura 2, pode-se observar a exata discriminação das ações de responsabilidade social segundo os setores econômicos. Esse fato pode ser verificado pela formação dos grupos, separados em quadrantes diferentes. Esse mapa evidencia que, no período analisado, houve uma tendência das empresas do setor energético de realizar investimentos em ações de responsabilidade social focadas na saúde. E as empresas dos setores bancário e petrolífero tenderam a investir mais em ações destinadas às atividades esportivas e de alimentação, combate à fome e segurança alimentar, respectivamente.

Dentre as organizações bancárias, cabe observar que o exame dos balanços sociais do período revela que o Banco do Brasil é responsável por 71,88\% do total investido pelo setor em esporte. $\mathrm{O}$ banco destinou recursos à Federação Nacional das Associações Atléticas Banco do Brasil (FENABB) (Relatório Anual do Banco do Brasil, 2003).

Novamente, observou-se um grande investimento em ações de combate à fome, realizadas desta vez pelo setor petrolífero. Outra análise abordou os investimentos de até $\mathrm{R} \$ 50$ milhões em educação, cultura e em ações de responsabilidade social rotuladas como "outros" (Tabela 5).

Os resultados encontrados na Tabela 6 justificam a construção do mapa bidimensional. A variabilidade total em quase $100 \%$ pode ser explicada pelos resultados do $1^{\circ}$ componente.

Enfim, após a verificação do número de componentes, procedeu-se à análise dos perfis, sendo os resultados mostrados na Figura 3. Os resultados evidenciados no mapa perceptual da Figura 3 mostram a discriminação das ações de responsabilidade social de acordo com os setores econômicos. Esse fato pode ser verificado pela formação dos grupos, separados em quadrantes diferentes.

De acordo com os resultados do mapa perceptual, observa-se que houve uma tendência das empresas do setor energético de realizar investimentos até $\mathrm{R} \$ 50$ milhões em ações focadas em cultura e educação. Observa-se que empresas do setor bancário tenderam a investir mais em outras ações de responsabilidade social rotuladas como "outros".

Tabela 5:

Frequência do número de empresas classificadas de acordo com os setores econômicos que realizaram investimentos até $R$ \$ 50 milhões em ações de 
responsabilidade social com foco na educação, cultura e outras ações de responsabilidade social não discriminada

\begin{tabular}{llll}
\hline \multirow{2}{*}{ Setores } & Ações & & \\
\cline { 2 - 4 } & Educação & Cultura & $\begin{array}{l}\text { Ações de responsabilidade social } \\
\text { rotuladas como "outros" }\end{array}$ \\
\hline Bancário & 5 & 4 & 6 \\
Energético & 27 & 28 & 15 \\
Siderúrgico & 2 & 2 & 2 \\
\hline
\end{tabular}

Fonte: Elaborada a partir dos dados da pesquisa (2014).

Tabela 5:

Análise dos componentes principais da tabela de contingência

\begin{tabular}{|c|c|c|c|c|c|}
\hline & Component & Autovalo & & Proporçã & Proporção \\
\hline $\mathrm{e}$ & & & 0 & & acumulada \\
\hline & 1 & 0.0283 & & 0.9964 & 0.9964 \\
\hline & 2 & 0.0001 & & 0.0036 & 1.0000 \\
\hline & Total & 0.0284 & & & \\
\hline
\end{tabular}

Fonte: Elaborada a partir dos dados da pesquisa (2014).

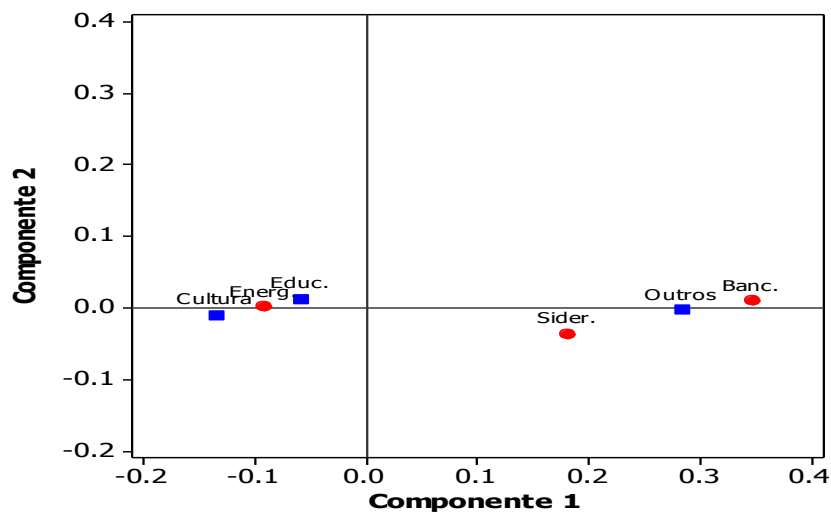

* Outros - investimentos em ações de responsabilidade social que não foram discriminados pelas empresas.

Figura 3. Mapa perceptual do perfil dos investimentos em ações de responsabilidade social até $\mathbf{R} \$$ 50 milhões de acordo com o setor econômico

Fonte: Elaborada a partir dos dados da pesquisa (2014).

$\mathrm{O}$ exame dos relatórios anuais das empresas do setor energético revela que os investimentos em cultura contemplaram filmes, festivais, apoio a museus, publicação de romances em braile, exibição de filmes em praças e escolas públicas, ou seja, projetos dos mais diversos segmentos da produção artística e cultural. Quanto aos investimentos em educação, verificou-se que foram realizadas doações a instituições de ensino.

Cabe aqui, um questionamento em relação aos investimentos dos setores bancário e siderúrgico: quais investimentos foram alocados nas ações de responsabilidade social rotuladas como "outros"? Seria interessante que fosse averiguado que tipo de investimento as empresas declararam nesse quesito. Essa informação poderia contribuir com uma maior transparência e credibilidade dos dados contidos no balanço social. 
Por fim, foram analisados os investimentos acima de $\mathrm{R} \$ 100$ milhões feitos em ações de responsabilidade social destinadas à educação, cultura e ações de responsabilidade social rotuladas como "outros". A Tabela 7 e a Tabela 8 apresentam os resultados dessa análise.

Tabela 6:

Frequência do número de empresas classificadas de acordo com os setores econômicos que realizaram investimentos acima de $R$ \$ 100 milhões em ações de responsabilidade social com foco na educação, cultura e em ações de responsabilidade social rotuladas como "outros"

\begin{tabular}{llll}
\hline \multirow{2}{*}{ Setores } & Ações & & \\
\cline { 2 - 4 } & Educação & Cultura & $\begin{array}{l}\text { Ações de responsabilidade social } \\
\text { rotuladas como "outros" }\end{array}$ \\
\hline Bancário & 4 & 5 & 3 \\
Energético & 1 & 1 & 11 \\
Petrolífero & 1 & 1 & 1 \\
\hline
\end{tabular}

Fonte: Elaborada a partir dos dados da pesquisa (2014).

Tabela 7:

Análise dos componentes principais da tabela de contingência

\begin{tabular}{llll}
\hline Componente & Autovalor & Proporção & Proporção acumulada \\
\hline 1 & 0.3386 & 0.9970 & 0.9970 \\
2 & 0.0010 & 0.0030 & 1.0000 \\
\hline Total & 0.3396 & & \\
\hline
\end{tabular}

Fonte: Dados da Pesquisa (2014).

De acordo com os resultados da Tabela 8 verifica-se que a porcentagem da variabilidade total é explicada pelo $1^{\circ}$ componente $(99,70 \%)$. Tal resultado permite inferir uma alta dependência dos níveis categóricos nessas duas variáveis.

Após a verificação do número de componentes, procedeu-se à análise dos perfis, sendo os resultados apresentados no mapa perceptual da Figura 4. Esse mapa evidencia a discriminação das a ções de responsabilidade social de acordo com os setores econômicos, fato que pode ser verificado pela formação dos grupos, separados em quadrantes diferentes. Nos resultados desse mapa, observa-se uma tendência, tanto nas empresas do setor bancário quanto no setor petrolífero, de investirem em ações culturais e esportivas, respectivamente.

Os balanços sociais das empresas estudadas mostram que, no setor bancário, $\mathrm{R} \$$ 702.980 milhões foram investidos em projetos culturais no período de 2000 a 2006. Novamente, o Banco do Brasil foi o maior investidor entre 2001 e 2005 (R\$ 176.023.milhões, ou seja, 33,68\% do montante investido nesse período). Quanto aos montantes investidos pelo setor petrolífero, nos últimos cinco anos a Petrobrás, única empresa do setor estudada nesse trabalho, destinou sozinha, $\mathrm{R} \$ 1.060 .592$ bilhão aos programas culturais direcionados à sociedade. Segundo o relatório anual de 2006 da Petrobrás, a empresa "mantém a posição de maior patrocinadora cultural do País, com investimento anual de R $\$ 288$ milhões e mais de mil projetos em andamento" (Relatório Anual da Petrobrás, 2006, p. 74). Ressalta-se que, no ano de 2001, a Petrobrás foi a maior incentivadora dos projetos contemplados com o apoio da Lei Rouanet e do Audiovisual (Instituto Cultural Cidade Viva, 2003). 


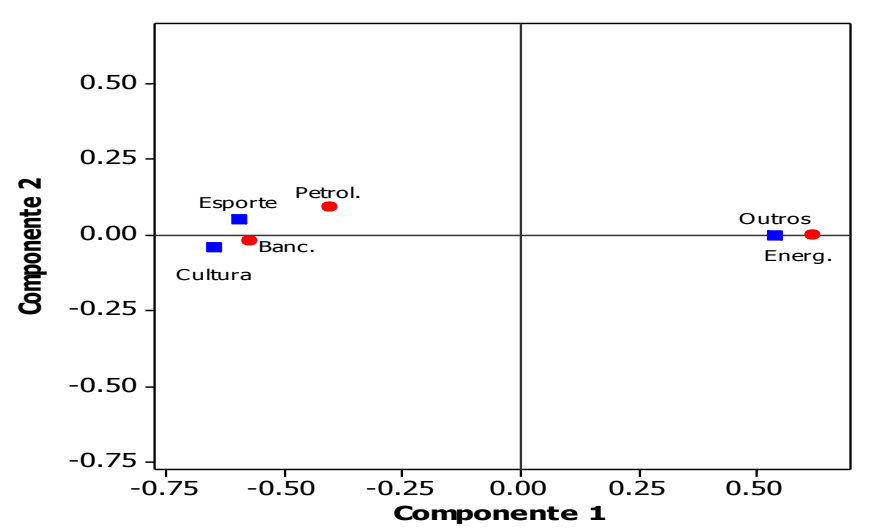

* Outros - investimentos em ações de responsabilidade social rotuladas como "outros" de acordo com os balanços sociais disponíveis nos relatórios anuais das empresas estudadas.

Figura 4. Mapa perceptual do perfil dos investimentos em ações de responsabilidade social acima de $\mathbf{R} \mathbf{1 0 0}$ milhões de acordo com o setor econômico

Fonte: Elaborada a partir dos dados da pesquisa (2014).

Em relação aos investimentos no esporte, o setor petrolífero destinou no período estudado R\$ 211.633 milhões. Os recursos patrocinaram equipes uma equipe de Fórmula 1, o automobilismo, esportes náuticos, eventos de surfe e a seleção brasileira de handebol (Relatório Anual da Petrobrás, 2003).

Outro resultado visível no mapa perceptual da Figura 4 diz respeito às empresas do setor energético. O mapa demonstra que as empresas desse setor tenderam a investir em ações de responsabilidade social que não foram discriminadas. Mais uma vez, cabe aqui o mesmo questionamento feito em relação aos investimentos dos setores bancário e siderúrgico: quais investimentos realizados pelas empresas do setor energético foram alocados nas ações de responsabilidade social rotuladas como "outros"?

Por fim, a Tabela 9 expõe uma síntese dos resultados obtidos a partir da análise de correspondência envolvendo as ações de responsabilidade social e os investimentos dos setores bancário, energético, siderúrgico e petrolífero.

De forma geral, as empresas estudadas tenderam a realizar mais investimentos na faixa de $\mathrm{R} \$ 10$ milhões e na faixa acima de $\mathrm{R} \$ 100$ milhões. As empresas do setor energético são as únicas que realizam investimentos em todas as faixas, com destaque para as faixas de $\mathrm{R} \$ 10$ milhões e $\mathrm{R} \$ 50$ milhões. Ressalta-se, ainda, que o setor energético só não investiu em ações de responsabilidade com foco em alimentação, combate à fome e segurança alimentar. Os setores bancário e petrolífero realizaram investimentos acima de $\mathrm{R} \$ 100$ milhões, especificamente em ações direcionadas à educação e cultura. Por fim, as empresas do setor siderúrgico tenderam a realizar investimentos na faixa dos $\mathrm{R} \$ 10$ milhões, preferencialmente em atividades educacionais e de saúde e saneamento. Esses resultados sugerem haver relação entre o perfil de investimentos em ações de responsabilidade social e o setor econômico.

Tabela 9:

Perfil dos investimentos dos setores bancário, energético, siderúrgico e petrolífero em ações de responsabilidade social

\begin{tabular}{l|l|l|l|l|l}
\hline $\begin{array}{l}\text { Faixas de } \\
\text { investimentos }\end{array}$ & $\begin{array}{l}\text { Até R\$ 10 } \\
\text { milhões }\end{array}$ & $\begin{array}{l}\text { Até R\$ 20 } \\
\text { milhões }\end{array}$ & $\begin{array}{l}\text { Até } \\
\mathrm{R} \$ 50 \text { milhões }\end{array}$ & $\begin{array}{l}\text { Acima } \\
\text { de R\$ 100 milhões }\end{array}$ \\
\hline
\end{tabular}




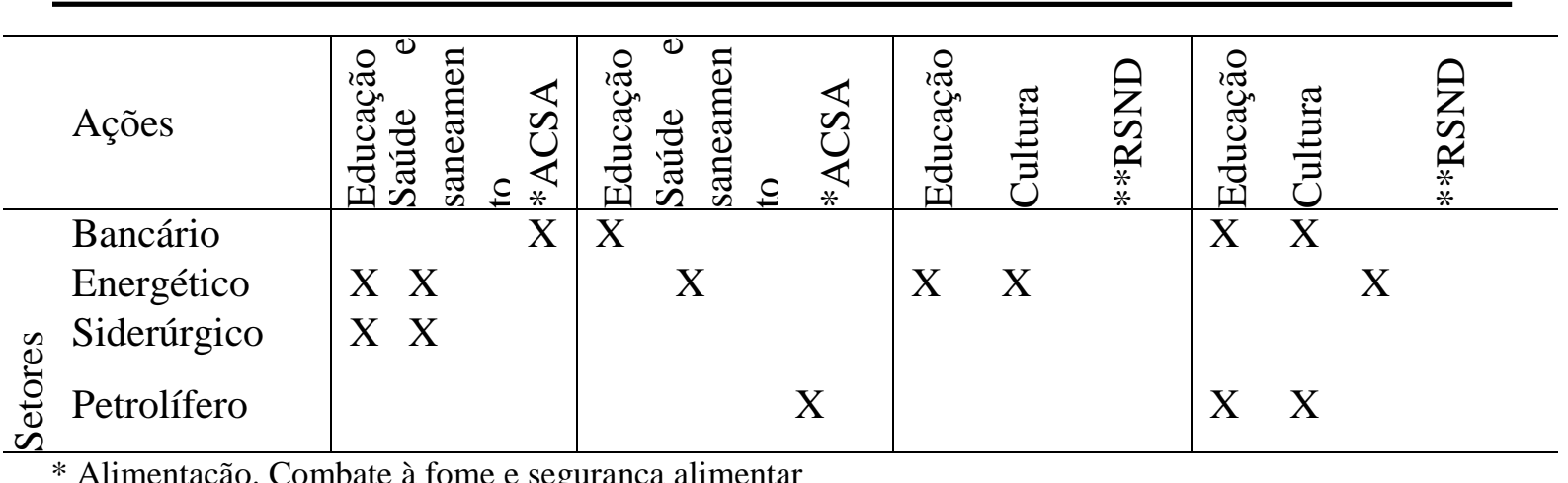

* Alimentação. Combate à fome e segurança alimentar

** Ações de responsabilidade social rotuladas como "outros"

Fonte: Elaborada a partir dos dados da pesquisa (2014).

\section{CONSIDERAÇÕES FINAIS}

Esta pesquisa teve por objetivo investigar se os investimentos em ações de responsabilidade social variam de acordo com setor econômico das empresas que os realizam. No intuito de esclarecer essa questão foram analisados de forma quantitativa os montantes designados ao longo de 10 anos à ações focadas em educação; saúde; cultura; alimentação, combate à fome e segurança alimentar bem como aquelas que não foram discriminadas pelas empresas. A amostra contemplou os investimentos de 42 empresas que publicam regularmente seus balanços sociais, sendo 10 organizações do setor bancário, 29 do setor energético, 02 do setor siderúrgico e 01 do setor petrolífero.

A análise de correspondência, técnica utilizada no tratamento dos dados mostrou que, de modo geral, há relação entre o perfil de investimentos em ações de responsabilidade social e o setor econômico. Os resultados apontaram que, tanto o Banco do Brasil como a Petrobrás, empresas de controle estatal, foram as maiores investidoras em ações de responsabilidade social no período estudado. Essa constatação desperta questionamentos sobre quem, de fato, está promovendo ações de responsabilidade social no país: o Estado, a sociedade ou ambos?

Outra constatação diz respeito à importância de aprimoramento do modelo de balanço social. Visto que, segundo (Bernardo, 2010, p. 24, é um "instrumento legitimado perante a sociedade" brasileira para a divulgação das práticas de responsabilidade social, destaca-se a necessidade de expandir os estudos sobre esse demonstrativo no país. Desse modo, seria possível conhecer as motivações para a sua elaboração bem como a eficácia dos indicadores contidos nesse demonstrativo para a tomada de decisão, dentre outros aspectos (Belal, 2001). Por fim, ressalta-se que os resultados do trabalho podem auxiliar os setores estudados em futuras decisões de investimentos sociais.

Como limitações da pesquisa deve-se considerar que o estudo abordou quatro setores: bancário, energético, siderúrgico e petrolífero. Nesse sentido, a expansão da pesquisa para outros ramos empresariais permitiria conhecer se também há relação entre esses setores e determinadas práticas de responsabilidade social.

Ademais, no intuito de facilitar a obtenção das informações para efetuar as análises, a amostra foi formada considerando-se dois aspectos: $\left(1^{\circ}\right)$ ser uma empresa de capital aberto e $\left(2^{\circ}\right)$ ter publicados seus balanços sociais nos relatórios anuais, no período estudado. Nesse contexto, seria interessante ampliar o universo de empresas a serem pesquisadas englobando aquelas de capital fechado ou que tenham divulgado de outra forma as informações sobre as atividades de responsabilidade social. 


\section{REFERÊNCIAS BIBLIOGRÁFICAS}

Ashley, P. A. (2005). Ética e responsabilidade social nos negócios. (2a ed.). São Paulo: Saraiva.

Associação Brasileira de Normas Técnicas [ABNT]. (2004). Norma Brasileira ABNT NBR 16001- Responsabilidade social - Sistema da gestão - Requisitos. (1a ed.) Disponível em: <http:// http://www.mj.gov.br/corde/arquivos/ABNT/nbr16001.pdf>. Acesso em: 19 set. 2009.

Banco do Brasil (2003). Relatório Anual do Banco do Brasil. Disponível em: <http://www.bb.com.br/docs/pub/siteEsp/ri/pt/dce/dwn/RA2003.pdf >. Acesso em: 10 nov. 2009.

Banco do Brasil (2005). Relatório Anual do Banco do Brasil. Disponível em: <http://www.bb.com.br/docs/pub/siteEsp/ri/pt/dce/dwn/RA2005.pdf >. Acesso em: 10 nov. 2009.

Bernardo, D. C. R. (2010). Ações de responsabilidade social empresarial e incentivos fiscais no Brasil. Tese de doutorado, Universidade Federal de Lavras, Lavras, MG, Brasil.

Bolsa de Valores de São Paulo [BOVESPA] (2009). Índice de Sustentabilidade Empresarial - ISE. Disponível em: <http://www.bovespa.com.br/pdf/Indices/ResumoISENovo.pdf >. Acesso em: 27 out. 2009.

Borger. F. G. (2001). Responsabilidade social: efeitos da atuação social na dinâmica empresarial. Tese de doutorado, Universidade de São Paulo, SP, Brasil.

Brasil (2007). Lei $\mathbf{n}^{\circ}$ 11.638, de 28 de dezembro de 2007. Altera e revoga dispositivos da Lei no 6.404, de 15 de dezembro de 1976, e da Lei no 6.385, de 7 de dezembro de 1976, e estende às sociedades de grande porte disposições relativas à elaboração e divulgação de demonstrações financeiras. Brasília: Presidência da República. Disponível em: <http://www.cultura.gov.br/site/categoria/apoio-aprojetos/mecanismos-de-apoio-do-minc/lei-rouanet-mecanismos-de-apoio-do-mincapoio-a-projetos/informacoes-gerais-lei-rouanet-mecanismos-de-apoio-do-minc-apoioa-projetos-mecanismos-de-apoio-do-minc-apoio-a-projetos/legislacao-especifica/> . Acesso em: 17 out. 2010.

Cappellin, P., \& Giuliani, M. (1999). Compromisso social no mundo dos negócios. In: Boletim do IBASE "Orçamento e Democracia”, Rio de Janeiro, v. 6, n. 11, p. 10-11, fev. 1999.

Carvalho, M. S., \& Strunchiner, C. J. (1992). Análise de Correspondência: uma aplicação do método à avaliação de serviços de vacinação. Caderno de Saúde Pública, Rio de Janeiro, 8 (3), 287-301.

Com Ciência, Revista Eletrônica de Jornalismo Científico (2006). Novo índice avalia sustentabilidade das empresas. Disponível em: <http://www.comciencia.br/noticias/2006/01/sustentabilidade.htm>. Acesso em: 20 set. 2009.

Comissão de Valores Mobiliários (2010). Empresas. Disponível em: <http:/www.cvm.gov.br>. Acesso em: 30 out. 2010.

Conselho Federal de Contabilidade. Normas Brasileiras de Contabilidade/ NBC T 15: informações de natureza social e ambiental. Disponível em: <http://www.portaldecontabilidade.com.br/nbc/t15.htm>. Acesso em: 28 set. 2009. 
Ferrel, O. C., Fraedrich J., \& Ferrel, L. (2001). Ética Empresarial: dilemas, tomadas de decisão e casos. Rio de Janeiro: Reichmann \& Affonso.

Freire, F. S., \& Silva, T. R. (2001). Uma descrição sucinta do Balanço Social francês, português, belga e brasileiro. In: Silva, C. A. T., \& Freire, F. S. (Org.). Balanço social: teoria e prática (pp. 69-115). São Paulo: Atlas.

Friedman, M. (1962). Capitalism and freedom. Chicago: University of Chicago Press. Froes, C., \& Melo Neto, F. P. (1999). Responsabilidade social e cidadania empresarial: a administração do terceiro setor. Rio de Janeiro: Qualitymark.

Garcia, J. (2004). O negócio do Social. Rio de Janeiro: Jorge Zahar Editor.

Greenacre, M. J. (1984). Theory and applications of correspondence analysis. London: Academic.

Instituto Brasileiro de Análises Sociais e Econômicas [IBASE] (2009). Banco de Dados. Disponível em: 〈http:/www.balancosocial.org.br〉. Acesso em: 11 out. 2009

Instituto Brasileiro de Análises Sociais e Econômicas [IBASE] (2009). Balanço Social. Disponível em: <http://www.balancosocial.org.br/cgi/cgilua.exe/sys/start.htm>. Acesso em: 03 dez. 2010.

Instituto Cultural Cidade Viva (2003). Perfil das empresas patrocinadoras. Rio de Janeiro: Record.

Instituto Ethos (2009a). Indicadores Ethos de Responsabilidade Social. Disponível em: <http://www.ethos.org.br/docs/conceitos_praticas/indicadores/default.asp>. Acesso em: 21 set. 2009.

Instituto Ethos (2009b). Responsabilidade social empresarial. Disponível em: <http://www1.ethos.org.br/EthosWeb/Default.aspx>. Acesso em: 21 set. 2009.

Kroetz, C. E. S. (2000). Balanço social: teoria e prática. São Paulo: Atlas.

Lourenço, A. G., \& Schröder, D. S. (2003). Vale investir em responsabilidade social empresarial? Stakeholders, ganhos e perdas. In: Instituto Ethos. Responsabilidade social das empresas: a contribuição das universidades (vol. 2, pp. 79-120). Peirópolis: Instituto Ethos,

Malhotra, N. K. (2001). Pesquisa de Marketing: uma orientação aplicada. (3a ed.). Porto Alegre: Bookman.

Murthy, V. (2008). Corporate social disclosure pratices of tops software firms in Índia. Global Business Review, London, 9 (2), 173-188.

Oliveira, J. A. P. (2008). Empresas na sociedade: sustentabilidade e responsabilidade social. Rio de Janeiro: Elsevier.

Petrobrás (2006). Relatório anual da Petrobrás. Disponível em: <http://www2.petrobras.com.br/ri/port/ConhecaPetrobras/RelatorioAnual/pdf/Relatorio Anual_2006.pdf >. Acesso em: 10 nov. 2009.

Srour, R. H. (2000). Ética empresarial: posturas responsáveis nos negócios, na política e nas relações pessoais. Rio de Janeiro: Campus.

Souza, H. (n.d.). Mensagem do Betinho. Disponível em: <http:/www.balancosocial.org.br>. Acesso em: 11 set. 2009.

Sucupira, J. A. (2009). Responsabilidade social das empresas. Disponível em: <http:/www.balancosocial.org.br>. Acesso em: 11 out. 2009.

Tenório, F. G. (2006). Responsabilidade Social: teoria e prática. (2a ed., rev. e ampl.). Rio de Janeiro: Editora FGV.

TINOCO, J. E. P. (2001). Balanço social: uma abordagem da transparência e da responsabilidade pública das organizações. São Paulo: Atlas. 
i Segundo Oliveira (2008, p. 2) “(...) responsabilidade social corporativa (RSC)”. 